\title{
PENGEMBANGAN MEDIA PEMBELAJARAN BERBASIS LIFE SKILL UNTUK SISWA SMK JURUSAN TEKNIK INSTALASI TENAGA LISTRIK
}

\author{
Despaleri Perangin-angin ${ }^{1}$, Christin Erniati Panjaitan ${ }^{1}$, Eka Dodi Suryanto ${ }^{2}$ \\ ${ }^{1}$ Universitas Prima Indonesia, ${ }^{2}$ Universitas Negeri Medan \\ IIdespanangin@gmail.com, ${ }^{1}$ christin.erniati@gmail.com, ${ }^{2}$ ekadodisuryanto@gmail.com
}

\begin{abstract}
Abstrak: Media pembelajaran menjadi pilihan untuk menunjang proses belajar yang menyenangkan dan menarik bagi siswa dan juga memperkuat motivasi, serta untuk menanamkan pemahaman pada siswa tentang materi yang diajarkan. Tujuan penelitian ini adalah mengembangkan media pembelajaran interaktif berbasis Life Skill untuk siswa SMK Jurusan Teknik Instalasi Tenaga Listrik. Penelitian ini menggunakan model penelitian dan pengembangan. Prosedur pengembangan media pembelajaran yang digunakan dalam penelitian ini mengadaptasi dari model ADDIE. Selanjutnya dilakukan validasi pada media yang telah dirancang. hasil penelitian ini yaitu pengembangan media pembelajaran berada dalam kategori Sangat Baik, berdasarkan penilaian dan validasi dari ahli media, ahli materi dan respon siswa. Hasil validasi dari ahli Media memperoleh rata-rata 93,33\%, ahli materi 88,33\% dan respon siswa sebagai pengguna adalah 90\%. Dengan hasil ini, media pembelajaran yang dikembangkan dapat diterapkan dalam proses belajar mengajar sesuai dengan materi dan kompetensi yang akan dicapai.
\end{abstract}

Kata Kunci: Media Pembelajaran, Life Skill, SMK, Teknik Instalasi Tenaga Listrik.

\begin{abstract}
Learning media is an option to support a fun and interesting learning process for students and also strengthen motivation, and to instill understanding in students about the material being taught. The purpose of this study was to develop Life Skill-based interactive learning media for Vocational High School Electrical Power Installation Engineering students. This study uses a research and development model. The learning media development procedure used in this study adapted from the ADDIE model. Furthermore, validation is carried out on the media that has been designed. The results of this study are the development of learning media in the Very Good category, based on the assessment and validation of media experts, material experts and student responses. The results of the validation of the media expert obtained an average of $93.33 \%$, the material expert was $88.33 \%$ and the student response as a user was $90 \%$. With these results, the learning media developed can be applied in the teaching and learning process in accordance with the material and competencies to be achieved..
\end{abstract}

Keywords: Learning Media, Life Skills, Vocational High School, Electrical Power Installation Engineering.

\section{PENDAHULUAN}

Pesatnya perkembangan ilmu pengetahuan dan teknologi dewasa ini membutuhkan kinerja pendidikan yang profesional dan berkualitas untuk mengatasinya. Dalam rangka mendukung terciptanya insan cerdas dan terampil maka kualitas dan pengembangan pendidikan ini sangat dibutuhkan agar mampu bersaing secara terbuka di era globalisasi. Artinya kita perlu memperhatikan pendidikan yang berkualitas dari dasar hingga lanjutan(Baharuddin, 2017:24).

Menurut Rayandra, pentingnya media dalam meningkatkan kualitas pembelajaran di Indonesia, tuntutan pasar global dan mata kuliah berbasis paradigma pembelajaran baru. Namun, media menghadapi dua masalah. Pembelajaran di lembaga pendidikan kita, media pembelajaran yang tersedia di berbagai sekolah masih kurang dan tidak seimbang. Ada beberapa sekolah yang bisa menyediakan banyak media, namun tidak banyak. Sebagian masyarakat masih belum memiliki berbagai jenis dan jumlah media pembelajaran yang dibutuhkan. Dari segi pengajar, beberapa orang menggunakan media secara maksimal, tetapi beberapa orang sedikit menggunakannya(Asyhar Rayandra, 2011:92).

Media yang paling sering digunakan adalah media cetak (buku teks, modul, catatan kuliah, buku teks, poster, majalah, koran, dll), sedangkan media sederhana yang masih digunakan adalah papan tulis. Media audiovisual (overhead transparansi, video / film, pita audio, TV / radio) dan media elektronik (komputer, internet) masih belum dimanfaatkan secara optimal, meskipun 
sudah digunakan di beberapa tempat(Baharuddin, 2017:24).

Penggunaan media pembelajaran juga erat kaitannya dengan peningkatan kualitas pembelajaran. Penggunaan media oleh pendidik dalam proses pembelajaran diharapkan dapat menciptakan suasana belajar dan pengalaman belajar yang lebih bermakna, serta memperkaya pengalaman belajar peserta didik. Dengan cara ini suasana belajar yang negatif dan membosankan dapat diubah menjadi aktif dan diiringi dengan partisipasi siswa yang lebih interaktif.

Rayandra Asyhar menyampaikan bahwa media pembelajaran dapat dipahami sebagai segala sesuatu yang dapat menyampaikan atau menyampaikan pesan dari sumbernya secara terencana, sehingga membentuk lingkungan belajar yang kondusif yang memungkinkan penerimanya dapat melaksanakan proses pembelajaran secara efektif. Sehingga materi pembelajaran dapat lebih cepat diterima siswa secara utuh, dan membangkitkan minat siswa untuk belajar lebih lanjut(Rayandra, 2011:8).

Dalam proses pembelajaran, pengertian media diartikan sebagai alat grafik, alat fotografi atau alat elektronik yang digunakan untuk menangkap, mengolah dan merekonstruksi informasi visual atau verbal. Media juga dapat diartikan sebagai segala sesuatu yang dapat digunakan untuk menyampaikan informasi, merangsang pikiran, perasaan, perhatian, dan keinginan siswa, sehingga mendorong mereka untuk berpartisipasi dalam proses pembelajaran..

Dengan kata lain, ada komunikasi antara siswa dan media, atau komunikasi tidak langsung antara siswa dengan pesan atau pendidik. Ketika kualitas siswa berubah, media dapat menyampaikan informasi pembelajaran dengan baik. Kehadiran media akan memungkinkan pendidik untuk meningkatkan minat siswa dalam proses pengajaran dan memungkinkan siswa untuk lebih cepat memahami dan memahami materi yang dikenalkan oleh pendidik.

Media interaktif merupakan suatu sistem penyampaian media yang dapat menampilkan materi rekaman kepada penonton (siswa) melalui kontrol komputer, penonton (audience) ini tidak hanya dapat mendengar dan melihat video dan suara, tetapi juga memberikan respon yang positif. Dan respon menentukan kecepatan dan urutan presentasi(Seels and Glasgow 1998). Media interaktif memiliki unsur audiovisual (termasuk animasi), sehingga disebut interaktif karena media tersebut dirancang untuk menyerap respon aktif pengguna. Selain itu, menurut Kamus
Besar Bahasa Indonesia (KBBI), media interaktif merupakan perantara atau alat komunikasi yang berkaitan dengan aktivitas timbal balik dan aktivitas komputer bersama.

Dengan bantuan media pembelajaran yang inovatif diharapkan proses pembelajaran menjadi inovatif, menarik, lebih interaktif, dan lebih efektif sehingga dapat meningkatkan kualitas belajar siswa.Proses pembelajaran dapat dilakukan dimanapun dan kapanpun serta sikap dan minat belajar siswa dapat ditingkatkan.

\section{Model Pembelajaran Problem-Based Learning}

Model pembelajaran yang digunakan juga harus dapat membantu proses belajar siswa. Salah satu model tersebut adalah pembelajaran berbasis masalah (PBL). Hmelo meyakini bahwa model "problem based learning" merupakan model pembelajaran yang membutuhkan aktivitas siswa yang cukup untuk secara mandiri menyelesaikan setiap masalah yang dihadapi siswa dengan mengkonstruksi pengetahuan dan pemahamannya (Evensen and Hmelo, 2013:235).

Menggabungkan konten di atas, mengadopsi inovasi model pembelajaran yang melibatkan lebih banyak partisipasi siswa melalui kolaborasi kelompok. Salah satu model pembelajaran yang digunakan adalah pembelajaran berbasis masalah (PBL)(Janah, dkk, 2018:2097). Model pembelajaran berbasis masalah merupakan model pembelajaran yang membutuhkan aktivitas siswa yang cukup untuk secara mandiri menyelesaikan setiap masalah yang dihadapi siswa dengan mengkonstruksi pengetahuan dan pemahamannya (Sasmita, 2015:75).

Model pembelajaran berbasis masalah memiliki banyak keunggulan, antara lain: (1) Model pembelajaran berbasis masalah dapat meningkatkan aktivitas siswa dalam proses pembelajaran; (2) Model pembelajaran berbasis masalah memberikan kesempatan kepada siswa untuk mengaplikasikan ilmunya pada kenyataan. (Wasonowati, and Ariani, 2014:66).

Pertanyaan kepada siswa sebelum mereka mempelajari konsep atau materi tentang masalah yang harus diselesaikan untuk merangsang keterampilan berpikir lanjutan. Hasil belajar merupakan kemampuan yang diperoleh siswa dalam proses pembelajaran.

Penerapan model PBL meliputi lima langkah utama, yaitu: orientasi siswa pada masalah, pengorganisasian siswa untuk pembelajaran, penyelidikan individu dan kelompok, pengembangan dan penyajian hasil, serta kegiatan 
analisis dan evaluasi. Menurut Bridges, model PBL dimulai dengan mengajukan pertanyaan, kemudian siswa menemukan dan menganalisis masalah melalui eksperimen langsung atau penelitian ilmiah (Bridges and Hallinger, 1996:55). Melalui kegiatan tersebut, proses dan kegiatan berpikir ilmiah siswa menjadi lebih logis, teratur dan menyeluruh, sehingga lebih mudah dalam memahami konsep (Belland, Ertmer and Simons, 1996:5).

Model PBL dipilih karena memiliki keunggulan sebagai berikut: 1) Masalah yang dipecahkan dapat menantang dan merangsang kemampuan berpikir kritis siswa, serta memberikan kepuasan dalam menemukan pengetahuan baru; 2) Pembelajaran dengan model PBL dianggap lebih menarik dan disukai siswa 3) Model PBL dapat meningkatkan aktivitas siswa dalam proses pembelajaran, dan 4) Model PBL dapat memberikan kesempatan kepada siswa untuk mengaplikasikan ilmunya ke dunia nyata (W. Gijselaers, 1996:15).

Keunggulan model PBL dalam pembelajaran juga didukung oleh beberapa hasil penelitian, diantaranya: 1) Suardana meyakini bahwa pembelajaran melalui PBL dapat meningkatkan kemampuan siswa dalam menemukan konsep dan menyelesaikan masalah(Suardana 2006), 2) Lightner percaya bahwa model PBL dapat membangun dan meningkatkan tingkat kolaborasi dan komunikasi antar siswa (Lightner, Bober and Willi, 2007:10), 3) Sahara meyakini bahwa dalam kegiatan pembelajaran yang menggunakan pembelajaran berbasis masalah (PBL), siswa dibiasakan untuk menemukan dan mengkonstruksi pengetahuannya sendiri, sehingga pembelajaran menjadi lebih bermakna (Sahala and Samad, 2010:86), dan 4) Mergendoller dan Bellisimo percaya bahwa model PBL dapat meningkatkan kemampuan aktivitas siswa, dan siswa dengan keterampilan sedang dan pengetahuan rendah akan belajar lebih aktif(Mergendoller, Maxwell and Bellisimo, 2006:50).

\section{Implementasi Kecakapan Hidup}

Menurut Mujakir kecakapan hidup adalah kemampuan dan keberanian untuk menghadapi masalah dalam hidup, kemudian secara aktif dan pasif mencari solusi untuk menyelesaikan masalah tersebut(MUJAKIR 2012:3). Selain itu, menurut Kiswoyowati, kecakapan hidup siswa mengacu pada kemampuan, kecakapan, dan kecakapan yang mereka butuhkan untuk menghadapi dan mengoperasinya dalam kehidupan nyata(Kiswoyowati 2011:4). Menurut Poerwati dan Amri menyatakan bahwa prinsip pelaksanaan pendidikan kecakapan hidup di SMK diutamakan kecakapan hidup vokasional (Poerwati and Amri 2013:175).

Kecakapan hidup dapat dibedakan menjadi lima kategori, yaitu: (1) Kecakapan kesadaran diri yang biasa disebut dengan keterampilan pribadi, meliputi penghayatan makhluk sebagai Tuhan Yang Maha Esa, anggota masyarakat dan warga negara; menyadari dan mensyukuri kelebihan dan kekurangan yang dimiliki, dan menjadikan Ini menjadi kondisi yang bermanfaat untuk meningkatkan diri dan menjadikan diri sendiri sebagai individu yang bermanfaat bagi diri sendiri dan lingkungan. (2) Kecakapan berpikir rasional (thinking skill) mencakup kecakapan menggali dan menemukan informasi, mengolah informasi, dan mengambil keputusan, memecahkan masalah secara kreatif. (3) Kecakapan sosial (social skill) mencakup kecakapan komunikasi dengan empati, bekerjasama, berempati, sikap penuh pengertian dan seni berkomunikasi dua arah. (4) Kecakapan akademik (academic skill) atau disebut kemampuan berpikir ilmiah (scientific method) mencakup antara lain identifikasi variabel, merumuskan hipotesis dan melaksanakan penelitian. (5) Kecakapan vokasional (vocational skill) atau keterampilan kejuruan, artinya keterampilan dikaitkan dengan bidang pekerjaan tertentu yang terdapat di masyarakat.

Pada mata kuliah 2013 jenis kecakapan hidup dijabarkan dalam jenis standar kompetensi sikap, pengetahuan dan kecakapan(E. Kosasih 2014:39). (1) Sikap dan kemampuan meliputi sikap mental (KI-1) dan sikap sosial (KI-2), sebagai keterampilan pribadi (pengenalan diri sebagai ciptaan Tuhan) dan perwujudan keterampilan sosial (a) keyakinan spiritual untuk mencapai keyakinan dan kekaguman. Abdi Tuhan. hanya. (B) Membangun sikap sosial masyarakat yang berakhlak mulia, sehat, mandiri, demokratis, dan bertanggung jawab. (2) Kemampuan Pengetahuan (KI-3) merupakan pelaksanaan pembelajaran keterampilan untuk mencakup masyarakat berpengetahuan. (3) Keterampilan Kemampuan (KI-4) mengacu pada penerapan kemampuan berpikir dan keterampilan vokasi manusia yang mewujudkan kemampuan dan kreativitas.

Berdasarkan uraian di atas, peneliti menyimpulkan bahwa yang dimaksud kecakapan hidup adalah kemampuan atau keterampilan seseorang dalam menghadapi problema kehidupan yang dihadapi kemudian secara 
proaktif dan reaktif dapat menemukan solusi untuk mengatasinya. Sedangkan pendidikan berorientasi kecakapan hidup menurut peneliti merupakan pendidikan yang menggunakan kecakapan hidup sebagai wadah untuk mensinergikan antara mata pelajaran dengan kasus di kehidupan nyata.

\section{METODE PENELITIAN}

Penelitian ini menggunakan model penelitian dan pengembangan. Model yang digunakan dalam pengembangan media pembelajaran ini merupakan kombinasi dari model pengembangan (Borg and Gall 1983) dan model pengembangan pembelajaran (Dick and Carey 2005).

Langkah-langkah dari tahap pengembangan yang dilakukan adalah sebagai berikut:

1) Potensi dan masalah, penelitian dipisahkan dari potensi dan masalah yang ada. Potensi mengacu pada segala sesuatu yang dapat menambah nilai setelah digunakan; 2) Mengumpulkan informasi Setelah menyadari dan memutakhirkan potensi dan masalah, maka perlu dikumpulkan berbagai informasi, yang dapat digunakan untuk merencanakan beberapa produk yang diharapkan dapat menyelesaikan masalah tersebut Bahan; 3) Produk yang dihasilkan dalam penelitian desain produk Research and Development bermacammacam. Di bidang teknologi, arah produk teknologi yang dapat digunakan untuk kehidupan manusia adalah kualitas, hemat energi, menarik, murah, ringan, ergonomis dan produk dengan banyak manfaat (misal produk dengan fungsi ganda, mengetik, menggambar Komputer dengan fungsi kompleks yang dapat digunakan sebagai TV, dll.). Dalam bidang pendidikan, produkproduk yang dihasilkan melalui penelitian Research and Development diharapkan dapat meningkatkan produktivitas pendidikan, yaitu jumlah lulusan yang banyak dengan kualitas tinggi dan terkait dengan permintaan; 4) Verifikasi desain: Verifikasi desain adalah proses kegiatan untuk mengevaluasi desain produk.Dalam hal ini, metode pengajaran yang baru secara teoritis lebih baik daripada yang lama. Metode pengajaran lebih efektif. Verifikasi produk dilakukan oleh beberapa ahli atau ahli berpengalaman untuk mengevaluasi produk baru yang dirancang. Setiap ahli diwajibkan untuk mengevaluasi desain agar dapat lebih menentukan kelemahan dan kekurangan produk. 5) Uji Coba Pada tahap ini dilakukan pengujian produk berupa media pembelajaran untuk mendapatkan masukan informasi terkait penggunaan.

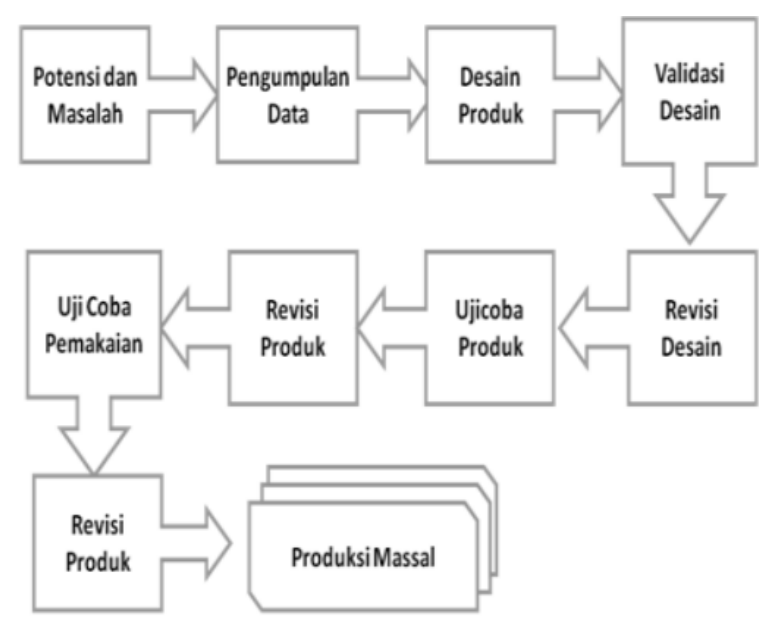

Gbr 1. Langkah-langkah model Research and Development (Sugiyono 2009:409)

Perancangan dan Pengembangan Media

Dalam penelitian ini, perancangan serta pengembangan dilakukan untuk mendapatkan produk berupa media pembelajaran. Prosedur pengembangan media pembelajaran yang digunakan dalam penelitian ini mengadaptasi dari model ADDIE yang dikembangkan oleh Dick and Carry. Model pengembangan ADDIE terdiri dari lima tahap yaitu: Analysis, Design, Development, Implementation, dan Evaluation(McGriff 2000).

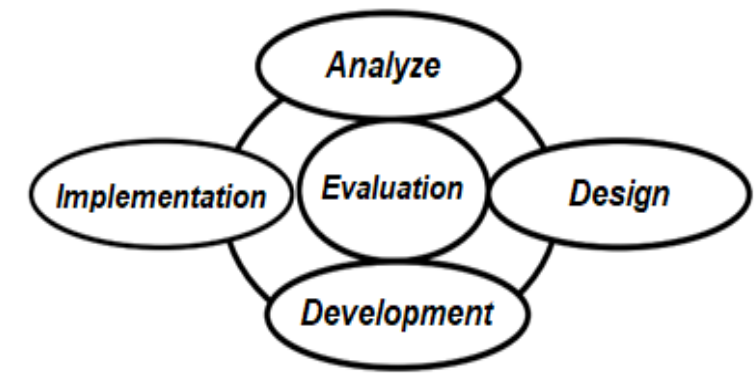

Gbr 2. Ilustrasi Model ADDIE(Dinatha dkk,2019)

Analisis (Analysis)

Tahap analisis merupakan suatu proses mendefinisikan apa yang akan dipelajari oleh peserta belajar, yaitu melakukan needs assessment (analisis kebutuhan),mengidentifikasi masalah (kebutuhan), dan melakukan analisis tugas (task analysis)(Baharuddin, 2017:28).

\section{Perancangan (Design)}

Pada tahap ini, yang dilakukan adalah merumuskan tujuan pembelajaran yang SMAR (spesifik, measurable, applicable, dan realistic). Selanjutnya menyusun tes, dimana tes tersebut harus didasarkan pada tujuan pembelajaran yag telah dirumuskan tadi. Kemudian tentukanlah strategi pembelajaran yang tepat harusnya seperti 
apa untuk mencapai tujuan tersebut. Dalam hal ini ada banyak pilihan kombinasi metode dan media yang dapat kita pilih dan tentukan yang paling relevan(Baharuddin, 2017:28).

\section{Pengembangan (Development)}

Pengembangan adalah proses mewujudkan desain menjadi kenyataan. Artinya, jika dalam desain diperlukan suatu software berupa multimedia pembelajaran, maka multimedia tersebut harus dikembangkan. Atau diperlukan modul cetak, maka modul tersebut perlu dikembangkan. Begitu pula halnya dengan lingkungan belajar lain yang akan mendukung proses pembelajaran semuanya harus disiapkan dalam tahap ini. Satu langkah penting dalam tahap pengembangan adalah uji coba sebelum diimplementasikan(Baharuddin, 2017:28).

\section{Implementasi (Implementation)}

Implementasi adalah langkah nyata untuk menerapkan sistem pembelajaran yang sedang kita buat. Artinya, pada tahap ini semua yang telah dikembangkan diinstal atau diset sedemikian rupa sesuai dengan peran atau fungsinya agar bisa diimplementasikan. Misal, jika memerlukan software tertentu maka software tersebut harus sudah diinstal. Jika penataan lingkungan harus tertentu, maka lingkungan atau seting tertentu tersebut juga harus ditata(Baharuddin, 2017:28).

\section{Evaluasi (Evaluation)}

Evaluasi adalah proses untuk melihat apakah sistem pembelajaran yang sedang dibangun berhasil, sesuai dengan harapan awal atau tidak. Sebenarnya tahap evaluasi bisa terjadi pada setiap empat tahap di atas. Evaluasi yang terjadi pada setiap empat tahap diatas itu dinamakan evaluasi formatif, karena tujuannya untuk kebutuhan revisi. Misal, pada tahap rancangan, mungkin kita memerlukan salah satu bentuk evaluasi formatif misalnya review ahli untuk memberikan input terhadap rancangan yang sedang kita buat(Baharuddin, 2017:28).

\section{Teknik Pengumpulan Data}

Untuk mendapatkan data secara tepat maka disusun instrumen dengan menggunakan angket. Angket dibuat secara terstruktur dengan bentuk pernyataan-pernyataan terbuka (open ended) untuk mendapatkan informasi yang dibutuhkan. Informasi yang diperoleh digunakan untuk kelengkapan teori, pengembangan model serta untuk apakah siswa dapat menggunakan media pembelajaran interaktif sesuai kebutuhannya (Baharuddin, 2017:29).

Selanjutnya dilakukan validasi pada media yang telah dirancang. Validasi digunakan untuk mengetahui kualitas perangkat pembelajaran yang dikembangkan. Validasi dilakukan dengan cara meminta para pakar atau ahli dalam bidang teknik elektro untuk memvalidasi atau menilai perangkat pembelajaran yang dikembangkan. Dalam hal ini diambil 3 (tiga) orang, masing-masing 2 (dua) orang dosen sebagai ahli media, 1 (satu) orang ahli materi dan 10 (sepuluh) orang siswa sebagai pengguna. Angket, digunakan untuk mengetahui tanggapan siswa terhadap kegiatan belajar mengajar. Instrumen yang digunakan pada teknik ini adalah instrumen respon siswa.

Analisis Data

Analisis validator dan respon siswa Tabel 1. Kriteria Penilaian

\begin{tabular}{cc}
\hline Kriteria & Bobot Nilai \\
\hline Sangat Setuju & 5 \\
Setuju & 4 \\
Cukup & 3 \\
Tidak Setuju & 2 \\
Sangat Tidak Setuju & 1 \\
\hline
\end{tabular}

Presentasi kualitas media pembelajaran diperoleh dari jumlah jawaban validator dan jumlah skor tertinggi validator. Setelah menganalisis jumlah total jawaban validator, langkah selanjutnya yaitu menentukan hasil rating penilaian validator menggunakan rumus:

$P=\frac{\text { SSkorValidator }}{\text { SSkorMaksimum }} \times 100 \%$ (Setiorini 2016)

Dari presentase yang diperoleh kemudian ditransformasikan kedalam tabel 2 berikut ini:

Tabel 2. Interval Kriteria Penilaian

\begin{tabular}{ccc}
\hline NO & INTERVAL & KRITERIA \\
\hline 1 & $81 \% \leq$ Skor $\geq 100 \%$ & Sangat Baik \\
2 & $61 \% \leq$ Skor $\geq 80 \%$ & Baik \\
3 & $41 \% \leq$ Skor $\geq 60 \%$ & Cukup Baik \\
4 & $21 \% \leq$ Skor $\geq 40 \%$ & Tidak Baik \\
5 & $0 \% \leq$ Skor $\geq 20 \%$ & Sangat Tidak Baik \\
\hline
\end{tabular}

(Sriadhi 2012)

\section{HASIL DAN PEMBAHASAN}

Hasil penelitian ini menunjukkan bahwa 
masalah yang dihadapi para siswa adalah kegiatan pembelajaran yang kurang interaktif. Metode ceramah membuat para siswa mengalami kejenuhan dalam mengikuti kegiatan belajar mengajar. Siswa menjadi kurang aktif dan berakibat pemahaman dan hasil belajar yang rendah. Berdasarkan observasi yang telah dilakukan, responden menyatakan bahwa dibutuhkan media interaktif untuk mempermudah siswa dalam kegiatan belajar mengajar.

Berdasarkan data hasil analisis kebutuhan yang telah dilakukan, selanjutnya dilakukan perancangan dan pengembangan untuk memenuhi kebutuhan. Peneliti merancang sebuah media yang mendukung proses kegiatan belajar mengajar. Media pembelajaran dirancang dengan menggunakan salah satu peralatan pengembang 3 dimensi. Media interaktif yang dirancang dikemas dalam bentuk animasi dengan kriteria: a) mudah dipelajari; b) desain tampilan menarik; c) materi mudah dimengerti; d) mudah dioperasikan pada komputer dengan spesifikasi rendah; e)dilengkapi dengan software pendukung.

Pada tahap pengembangan, media yang telah dirancang kemudian dibangun dengan menggunakan software pendukung. Pengembangan media pembelajaran interaktif mempertimbangkan beberapa hal, antara lain: a)mempermudah pengguna dalam mengikuti proses belajar mengajar; b) meningkatkan minat dan keaktifan siswa (interaktif); c) Audio yang jelas dan mudah dipahami; d) Animasi mencakup materi yang dipelajari dan kompetensi yang ingin dicapai; e) memberikan sistem penilaian sesuai dengan materi yang dipelajari.

Selanjutnya, media yang telah dikembangkan kemudian diimplementasikan pada proses belajar mengajar. Implementasi media pembelajaran dilakukan pada siswa SMK Jurusan Teknik Instalasi Tenaga Listrik. Siswa diberikan kompetensi dan materi yang akan dipelajari. Kemudian siswa diberikan animasi media pembelajaran interaktif untuk materi instalasi penarangan rumah sederhana. Siswa diberikan kebebasan untuk mempelajari materi dari media.

Tahap selanjutnya adalah evaluasi. Evaluasi dilakukan untuk mendaapatkan umpan balik terkait pemanfaatan produk kepada pengguna. Evaluasi media dilakukan dengan melakukan penilaian berupa validasi ahli untuk materi, media dan penilaian pengguna. Validasi media pembelajaran melibatkan 3 (tiga) orang ahli media dari kalangan dosen, 3 (tiga) orang ahli materi dari kalangan dosen dan guru produktif serta 10 orang siswa yang telah menggunakan media pembelajaran pada proses belajar mengajar.

Tabel 2. Hasil Validasi Ahli Media

\begin{tabular}{llcccrl}
\hline No Pernyataan & \multicolumn{2}{c}{ Ahli } & \multicolumn{2}{c}{$\begin{array}{c}\text { Rata- } \\
\text { Rata }\end{array}$} & Kategori \\
& & I & II & III & \\
\hline 1 & Valid & 4 & 5 & 4 & $87 \%$ & SB \\
2 & Keamanan & 5 & 5 & 4 & $93 \%$ & SB \\
3 & Learnability & 5 & 4 & 5 & $93 \%$ & SB \\
4 & Desain & 5 & 5 & 5 & $100 \%$ & SB \\
\hline
\end{tabular}

Hasil yang diperoleh dari validasi ahli media dengan rata-rata penilaian $93,33 \%$ atau dalam kategori Sangat Baik. Dengan hasil ini, dapat dikatakan bahwa penelitian pengembangan media pembelajaran telah selesai dan mencapai hasil maksimum. Berdasarkan hasil penilaian dari ahli media dapat disimpulkan bahwa media pembelajaran yang telah dikembangkan layak digunakan dalam proses belajar mengajar.

Evaluasi materi dilakukan melalui penilaian terstruktur oleh para ahli materi. Dalam penelitian ini, validasi materi dilakukan oleh 3 (tiga) orang ahli materi yang berasal dari kalangan dosen dan guru produktif.

Tabel 3. Hasil Validasi Ahli Materi

\begin{tabular}{|c|c|c|c|c|c|c|}
\hline \multirow[t]{2}{*}{ No } & \multirow[t]{2}{*}{ Pernyataan } & \multicolumn{3}{|c|}{ Ahli } & \multirow{2}{*}{$\begin{array}{l}\text { Rata- } \\
\text { Rata }\end{array}$} & \multirow[t]{2}{*}{ Kategori } \\
\hline & & I & II & III & & \\
\hline 1 & Kelayakan & 5 & 5 & 4 & $93 \%$ & SB \\
\hline 2 & Manfaat & 4 & 4 & 4 & $80 \%$ & SB \\
\hline 3 & Learnability & 4 & 4 & 5 & $87 \%$ & SB \\
\hline 4 & Menarik & 5 & 4 & 5 & $93 \%$ & SB \\
\hline
\end{tabular}

Berdasarkan data pada tabel 3, diperoleh hasil penilaian validasi dari ahli materi dengan nilai rata-rata $88,33 \%$ secara keseluruhan. Dengan nilai rata-rata yang diperoleh, dapat dikatakan bahwa materi yang disajikan dalam media pembelajaran interaktif berada dalam kategori Sangat Baik atau Sangat Layak. Sehingga dapat disimpulkan bahwa materi yang disajikan dapat digunakan pada proses belajar mengajar dan sesuai dengan kompetensi yang ingin dicapai.

Kemudian peneliti meminta respon dari 10 (sepuluh) orang siswa yang telah menggunakan media dalam proses belajar mengajar melalui angket. Angket yang diberikan kepada siswa berisi aspek penilaian terkait penggunaan media pembelajaran dalam proses belajar mengajar. Data hasil respon siswa ditunjukkan pada tabel 4 berikut ini.

Tabel 4. Hasil Respon Siswa

\begin{tabular}{llllllll}
\hline Siswa & \multicolumn{4}{c}{ Aspek } & & Rata- \\
& 1 & 2 & 3 & 4 & 5 & \\
\hline
\end{tabular}




\begin{tabular}{ccccccr}
\hline & & & & & & Rata \\
\hline A & 5 & 4 & 5 & 5 & 4 & $92 \%$ \\
B & 5 & 5 & 4 & 4 & 4 & $88 \%$ \\
C & 4 & 4 & 5 & 4 & 5 & $88 \%$ \\
D & 4 & 4 & 5 & 4 & 5 & $88 \%$ \\
E & 5 & 5 & 4 & 5 & 5 & $96 \%$ \\
F & 5 & 4 & 4 & 5 & 4 & $88 \%$ \\
G & 4 & 5 & 4 & 4 & 4 & $84 \%$ \\
H & 5 & 5 & 5 & 5 & 5 & $100 \%$ \\
I & 4 & 5 & 4 & 4 & 5 & $88 \%$ \\
J & 4 & 4 & 5 & 4 & 5 & $88 \%$ \\
\hline
\end{tabular}

Berdasarkan data hasil respon siswa pada tabel 4, diperoleh hasil penilaian dari respon siswa yang telah menggunakan media pembelajaran dalam proses belajar mengajar dengan nilai rata-rata 90\% secara keseluruhan. Dengan nilai rata-rata yang diperoleh dari respon siswa, dapat dikatakan bahwa pemanfaatan media pembelajaran yang dirancang berada dalam kategori Sangat Baik.

\section{PENUTUP}

Kesimpulan yang dapat ditarik dari penelitian ini adalah pengembangan media pembelajaran yang dikembangkan berada dalam kategori Sangat Baik berdasarkan penilaian dan validasi dari ahli media, ahli materi dan respon siswa. Hasil validasi dari ahli Media memperoleh ratarata $93,33 \%$, ahli materi $88,33 \%$ dan respon siswa sebagai pengguna adalah 90\%. Dengan hasil ini, media pembelajaran yang dikembangkan dapat diterapkan pada proses pembelajaran sesuai dengan materi dan kompetensi yang dicapai.

Untuk impllementasinya, guru produktif harus diberi penguatan untuk dapat mengembangkan media pembelajaran interaktif. Hal ini bertujuan agar pembelajaran lebih menarik dan siswa lebih aktif. Sehingga diharapkan hasil belajar siswa juga dapat meningkat.

\section{DAFTAR PUSTAKA}

Asyhar RayandAsyhar Rayandra. 2011. Kreatif Mengembangkan Media Pembelajaran. Jakarta: GP Press.

Baharuddin. 2017. "PENGEMBANGAN MEDIA PEMBELAJARAN INTERAKTIF SMK TERHADAP EFEKTIF DAN EFISIENSI PEMBELAJARAN." Jurnal Teknologi Informasi Dan Komunikasi Dalam Pendidikan 4(1):24-33.

Belland, B. R., P. A. Ertmer, and K. D. Simons. 1996. "Perceptions of the Value of ProblemBased Learning among Students with
Special Needs and Their Teachers." Interdisciplinary Journal of Problem-Based Learning 1(2):1-18.

Borg, W., and M. D. V. Gall. 1983. Educational Research. An Introduction (4nd Ed). New York \& London: Longman.

Bridges, M., and M. Hallinger. 1996. "Problembased Learning in Leadership Education." American Journal of Physics 60(7):53-62.

Dick, W., and L. Carey. 2005. The Systematic Design of Instruction. United States of America: Scott Foresman and Company.

Dinatha, Ngurah Mahendra, and Maria Yuliana Kua. 2019. "PENGEMBANGAN MODUL PRAKTIKUM DIGITAL BERBASIS NATURE OF SCIENCE ( NOS ) UNTUK MENINGKATKAN HIGHER ORDER THINKING SKILL ( HOTS ).” 3:293-300.

E. Kosasih. 2014. Strategi Belajar Dan Pembelajaran Implementasi Kurikulum 2013. Jakarta: Yrama Widya.

Evensen, Dorothy H., and Cindy E. Hmelo. 2013. Problem-Based Learning: A Research Perspective on Learning Interactions. edited by D. H. Evensen and C. E. Hmelo. New York: Routledge.

Janah, Mely Cholifatul, Antonius Tri Widodo, and Kasmui. 2018. "PENGARUH MODEL PROBLEM BASED LEARNING TERHADAP HASIL BELAJAR DAN KETERAMPILAN PROSES SAINS." Jurnal Inovasi Pendidikan Kimia 12(1):2097-2107.

Kiswoyowati, Amin. 2011. "Pengaruh Motivasi Belajar Dan Kegiatan Belajar Siswa Terhadap Kecakapan Hidup Siswa.” Portal Jurnal Universitas Pendidikan Indonesia Edisi Khus(1):120-26.

Lightner, Sharon, Marcie J. Bober, and Caroline Willi. 2007. "Team-Based Activities to Promote Engaged Learning." College Teaching 55(1):5-18.

McGriff, S. .. 2000. Instructional Systems. New York: College of Education, Penn State University.

Mergendoller, John M., Nan L. Maxwell, and Yolanda Bellisimo. 2006. "The Effectiveness of Problem-Based Instruction: A Comparative Study of Instructional Methods and Student Characteristics." The Interdisciplinary Journal of Problem-Based Learning 1(2):49-69.

MUJAKIR. 2012. "Pengembangan Life Skill Dalam Pembelajaran." Jurnal Ilmiah DIDAKTIKA XIII(1):1-13. 
Poerwati, Loeloek Endah, and Sofan Amri. 2013. Panduan Memahami Kurikulum 2013. Jakarta: Prestasi Pustaka.

Sahala, Stepanus, and Abdus Samad. 2010. "PENERAPAN PEMBELAJARAN MODEL MASALAH DALAM PEMBIASAN CAHAYA PADA LENSA TERHADAP HASIL BELAJAR SISWA DI KELAS VIII SMP NEGERI 5 KETAPANG." Jurnal Matematika Dan IPA 1(2):12-25.

SASMITA, ENDANG. 2015. "PENGARUH PROBLEM BASED LEARNING TERHADAP HASIL BELAJAR SISWA PADA MATA PELAJARAN GEOGRAFI."

Seels, Barbara, and Zita Glasgow. 1998. Making Instructional Design Decisions. (2nd Ed.). Upper Saddle River: NJ: Merrill.

Setiorini, Dyah. 2016. "PENGEMBANGAN PERANGKAT PEMBELAJARAN BERORIENTASI KECAKAPAN HIDUP (LIFE-SKILL) DENGAN MENERAPKAN MODEL PEMBELAJARAN KOOPERATIF TIPE STUDENT TEAMS ACHIEVEMENT DIVISIONS (STAD) UNTUK MENINGKATKAN HASIL BELAJAR PADA MATA PELAJARAN INSTALASI PENERANGAN LISTRIK." Jurnal Pendidikan Teknik Elektro 05(1):445-52.

Sriadhi. 2012. Instrumen Ukur Kelayakan Courseware Multimedia Learning. Kuala Lumpur: Centre for Instructional Technology and Multimedia USM.

Suardana, I. Nyoman. 2006. "PENERAPAN STRATEGI PEMBELAJARAN BERBASIS MASALAH DENGAN PENDEKATAN KOOPERATIF BERBANTUAN MODUL UNTUK MENINGKATKAN KUALITAS PROSES DAN HASIL BELAJAR MAHASISWA PADA PERKULIAHAN KIMIA FISIKA I." Jurnal Pendidikan Dan Pengajaran IKIP Negeri Singaraja 39(4):751-68.

Sugiyono. 2009. Metode Penelitian Pendidikan. Bandung: Alfabeta Bandung.

W. Gijselaers. 1996. "Connecting Problem-Based Practices with Educational Theory." American Journal of Physics 68(7):13-27.

Wasonowati, Ratna Rosidah Tri, Tri Redjeki, and Sri Retno Dwi Ariani. 2014. "PENERAPAN MODEL PROBLEM BASED LEARNING ( PBL ) PADA PEMBELAJARAN HUKUM - HUKUM DASAR KIMIA DITINJAU DARI AKTIVITAS DAN HASIL
BELAJAR SISWA KELAS X IPA SMA NEGERI 2 SURAKARTA TAHUN PELAJARAN 2013 / 2014.” Jurnal Pendidikan Kimia (JPK) 3(3):66-75. 